\title{
Filtración del enterococcus faecalis en obturaciones retrógradas con MTA, amalgama de plata e ionómero de vidrio
}

Enterococcus faecalis leakage in MTA, silver amalgam and glass ionomer as root-end filling materials

\begin{abstract}
Resumen
Uno de los objetivos del material de obturación retrograda colocado en un tratamiento de apicectomía es proporcionar sellado apical que inhiba la migración coronaria de antígenos hacia los tejidos perirradiculares. Muchos materiales son utilizados para este fin, sin embargo, a la fecha no se ha encontrado ningún material que satisfaga todos los requerimientos de un material ideal de obturación retrograda.

La presente investigación se hizo con el propósito de hacer un análisis comparativo de las propiedades de sellado apical de tres materiales de obturación retrograda: amalgama de plata, ionomero de vidrio y MTA (agregado de trioxido mineral), ante el proceso de filtracion de la bacteria Enterococus Faecalis y el tiempo empleado para filtrar vía coronaria hacia la zona perirradicular. La filtracion fue comprobada al virar el caldo de glucosa rojo de fenol, en el cual fueron sumergidos los apices de los dientes de estudio, a una temperatura de $37^{\circ} \mathrm{C}$. Los resultados demostraron que la frecuencia de especimenes que filtran en tiempos mayores a 70 días es significativamente más alta para los casos de cemento MTA, que para los otros dos materiales.
\end{abstract}

\begin{abstract}
One of the aims of a root-end filling material placed in an apicectomy treatment is to provide apical seal that can inhibits the coronary migration of antigens to perirradicular tissues. Many materials are used for this end; however, to date there has not been any material that satisfies all the requirements of an ideal material.

With the purpose of making a comparative analysis of the apical sealing abilities of three root-end filling materials: silver amalgam, glass ionomer and MTA (mineral trioxide aggregate), in the leakage process of Enterococcus Faecalis bacteria and the time used for it to leak via coronary toward the perirradicular area, the present investigation was made. Leakage was proven when veering the fenol red glucose, in which the apexes of the sample teeth were submerged, to a temperature of $37^{\circ} \mathrm{C}$. The results showed that specimens that leakage in longer than 70 days were significantly higher for the cases of cement MTA than for the other two materials.
\end{abstract}

\section{Introducción}

El principal objetivo del material de obturación retrograda es proporcionar sellado apical que inhiba la migración de antígenos desde el sistema de conductos hacia los tejidos perirradiculares. Harty y $\mathrm{col}^{(1)}$. reportaron que el sellado apical es el factor mas importante en logro del éxito de la Cirugía endodóntica.

De acuerdo con Gartner y Dorn (2), un material de obturación apical, debe ser: de fácil manipulación, radiopaco, dimensionalmente estable, no resorbible, no ser afectado por la presencia de humedad, deberá adherirse a las paredes de la preparación y sellar el sistema de conductos, no ser toxico, bien tolerado por los tejidos periapicales y promover la cicatrización. Además, no se debe corroer, ser eléctricamente activo o tatuar los tejidos perirradiculares.

Muchos materiales vienen siendo utilizados como materiales de obturación retrograda: gutapercha, eugenato de zinc, cavit, resina compuesta y hoja de oro ${ }^{(3,4)}$. Sin embargo, a la fecha no se ha encontrado ningún material que satisfaga todos los requerimientos de un material ideal de obturación retrograda.

\section{Martha Elena Pineda Mejía', Doris Salcedo Moncada', Antonia Castro Rodríguez ${ }^{4}$, Elmo Palacios Alva ${ }^{3}$, Hilda Moromi Nakata ${ }^{2}$, Elba Martínez Cadillo², Ántero Ortiz Cárdenas', Rómel Watanabe Velásquez', Livia Zambrano de la Peña ${ }^{3}$, Julio Ochoa Tataje ${ }^{1}$, Lourdes Lara Téllez' ${ }^{1}$, Gerardo Ayala de la Vega' ${ }^{1}$, María Ventocilla Huasupoma'}

Departamento Académico Estomatología Rehabilitadora.

Departamento Académico de Ciencias Básicas.

Departamento Académico Médico Quirúrgico.

4 Departamento Académico Estomatología Biosocial.

1-4 Facultad Odontología UNMSM. Lima Perú.

\section{Correspondencia:}

Mg. Martha Pineda Mejía

Facultad Odontología. UNMSM.

Av. Germán Amézaga s/n, Lima, 1 Perú. e-mail: mpinedam@unmsm.edu.pe

Palabras clave: Filtración. Enterococcus Faecalis, Obturación retrógrada.

Key words: Leakage. Enterococcus Faecalis Root-end filling material. MTA.
La amalgama ha sido criticada por su:

a) Filtración inicial b) Corrosión secundaria c) Contaminación de mercurio y estaño d) Sensibilidad a la humedad e) Necesidad de preparar un socavado retentivo en la preparación cavitaria f) Tatuado de tejidos duros y blandos g) Manejo y control de partículas esparcidas ${ }^{(2)}$.

El Agregado de Trioxido Mineral MTA viene siendo reportado como un material que sella todas las rutas de comunicación entre el sistema de conductos y la superficie externa del diente ${ }^{(5)}$. El polvo consiste de finas 
partículas hidrofílicas que fraguan en la presencia de humedad. La hidratación del polvo resulta en un gel coloidal que solidifica a una estructura dura en menor que $4 h^{(5)}$.

La efectividad de los materiales de obturación para proporcionar un sellado apical se evalúa mediante la penetración de tinta, radioisótopos, bacterias, acción electromecánica, microscopia electrónica de barrido, $\mathrm{y}$ filtración de fluidos. El método mas ampliamente usado es la técnica de filtración de tinta.

Sin embargo, a pesar de su popularidad, los estudios de penetración de tinta tienen varias desventajas: a) el tamaño molecular de la mayoría de partículas de tinta son mas pequeñas que la bacteria; b) la mayoría de estudios de filtración de tinta miden los grados de penetración de tinta en un plano, haciendo imposible evaluar la filtración total; y c) comparado con las condiciones clínicas, los estudios de tinta in vitro son estáticos y no reflejan la interacción dinámica entre los conductos radiculares y los tejidos perirradiculares $^{(7)}$.

Debido a las insuficiencias inherentes a los estudios de filtración de tinta y radioisótopos, y a una falta de correlación entre los estudios de filtración bacteriana, filtración de tinta y moléculas de radioisótopos, los estudios de filtración bacteriana han sido recomendados para probar la conveniencia de potenciales materiales de obturación retrograda ${ }^{(7)}$. Casos resistentes a la terapia endodóntica están asociados con la presencia de la bacteria Enterococcus Faecalis ${ }^{(11)}$.

Torabinejad y col. ${ }^{(5)}$ usaron tinta fluorescente rhodamine $\mathrm{B}$ y un mi- croscopio confocal para evaluar la habilidad de sellado de la amalgama, Super EBA, y MTA como materiales de obturación retrograda. El análisis estadístico de sus datos mostró que el MTA filtró significativamente menos que la amalgama o super EBA. En otro estudio usando la filtración bacteriana y una prueba de comparación múltiple, se mostró que no existía diferencia significante entre la filtración de la amalgama, Super EBA, y el Material Restaurativo Intermedio IRM. Sin embargo, si indico que el MTA filtró significativamente menos que otros materiales de obturación retrograda $(\mathrm{p}<0,05)^{(7)}$.

El propósito del presente estudio es establecer los tipos de materiales de obturación retrograda que vienen siendo empleados en los tratamientos de Cirugía Apical en la Clínica Central

\section{Control radiográfico de los grupos experimentales}
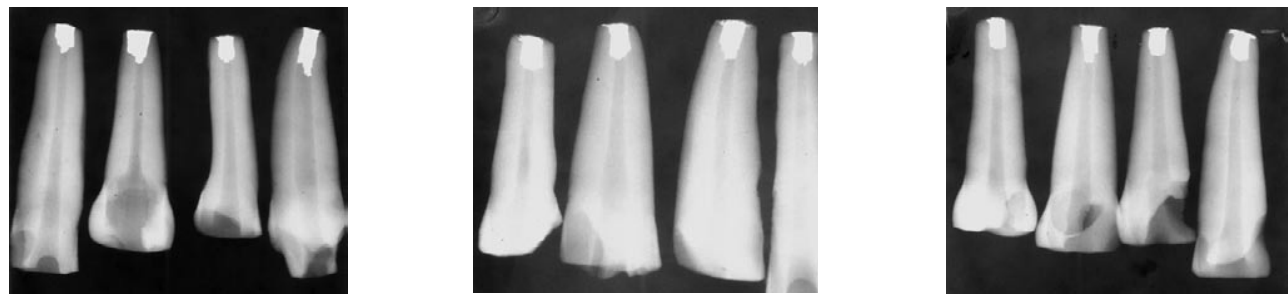

Fig, 1.2.3. Piezas dentarias cuyas cavidades retrógradas fueron obturadas con AMALGAMA DE PLATA EXENTA DE ZINC
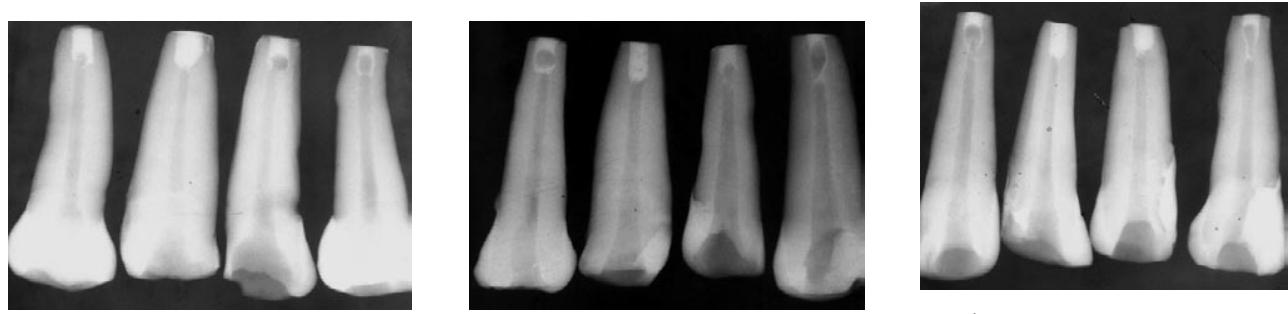

Fig, 4.5.6. Piezas dentarias cuyas cavidades retrógradas fueron obturadas con IONÓMERO DE VIDRIO

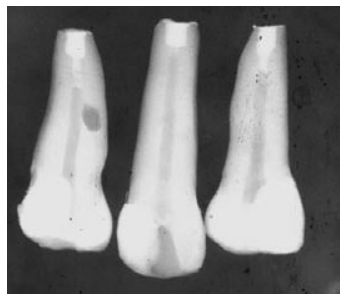

Fig, 7. Piezas dentarias que reemplazaron a aquellas obturadas con IONOMERO DE VIDRIO que fueron consideradas como deficiente.

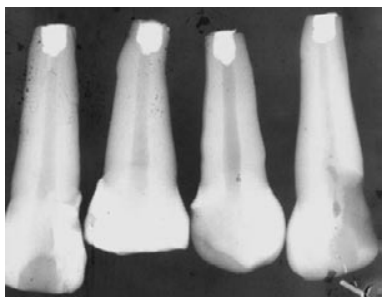

Fig.8. Piezas dentarias obturadas con gutapercha (control)
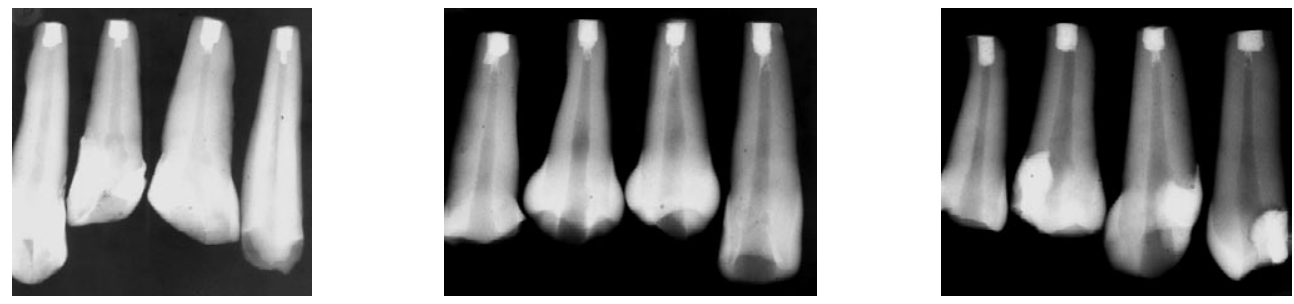

Fig, 9.10.11. Piezas dentarias cuyas cavidades retrógradas fueron obturadas con MTA 
de la facultad de Odontología de la UNMSM.

Determinar el tiempo requerido por la bacteria Enterococus Faecalis para filtrar $(3 \mathrm{~mm})$ coronalmente los materiales de obturación retrograda:

- Amalgama

- Ionomero de vidrio

- MTA (agregado de trióxido mineral)

Hacer un análisis comparativo del comportamiento de los diferentes materiales de obturación retrograda ante el proceso de filtracion bacteriana y de los tiempos empleados por la bacteria Enterococus Faecalis para filtrar hacia la zona perirradicular.

\section{Materiales y Método}

Muestra:

Se seleccionaron 44 dientes permanentes humanos, recientemente extraídos con los siguientes criterios de inclusión:

- Unirradicular

- Raíz recta

- Con un solo conducto

- Ápice cerrado.

Se conformaron los grupos experimentales en forma aleatoria, quedando la muestra definida de la siguiente manera:

- Obturación retrograda con amalgama: 12 dientes

- Obturación retrograda con ionómero de vidrio: 12 dientes

- Obturación retrograda con MTA: 12 dientes

- Control positivo (gutapercha): 04 dientes

- Control negativo: (cera mas barniz) 04 dientes

\section{Procedimientos}

Fase clínica:

Los dientes fueron almacenados en hipoclorito de sodio, antes de ser usados y mantenidos en humedad a través del experimento. Después de las radiografías iniciales, para confirmar criterios de inclusión, se prepararon cavidades de acceso coronal, para luego obtener una longitud de trabajo con una lima \# 15, restando $1 \mathrm{~mm}$ de la longitud obtenida desde un punto de referencia coronal hasta su visualización en el agujero del foramen apical.

Los conductos fueron preparados con una técnica corono apical rotatoria, mediante el uso del sistema de limas PROTAPER (DENTSPLY, Maillefer, Swiss), con un reductor ENDOMATE TC (NSK, Japan). Para obtener un diámetro estándar, el foramen apical de cada diente se patentizó hasta una lima \# 40. Se irrigaron los conductos para eliminar el barro dentinario con hipoclorito de sodio al 2,5\%.

Luego utilizando una fresa de fisura se procedió al corte de los $3 \mathrm{~mm}$ apicales de cada raíz en un ángulo de 90 grados con relación al eje longitudinal del diente.

En la zona del corte apical se prepararon cavidades de $3 \mathrm{~mm}$ de profundidad para albergar la obturación retrograda. Luego se procedió a la esterilización de los dientes en una autoclave por $30 \mathrm{~min}$. a $121^{\circ} \mathrm{C}$. Una lima estéril \#70 fue colocada por el acceso coronal, hacia apical, dejando los 3,0 mm de la cavidad apical libres en la zona del ápice, para proceder a la obturación retrograda.

Un grupo de 12 dientes fueron obturados con Amalgama libre de zinc VIVALLOY - HR non gamma 2 (VIVADENT Schaan, Liechtenstein, Sweden), preparado en amalgamador.

Otro grupo similar con Ionomero de Vidrio GC Fuji II LC (GC Corporation, Tokio, Japan), sistema de polvo y liquido, procediéndose primero al tratamiento de la dentina cavitaria con ácido poliacrilico al 10\%.

Un tercero grupo con MTA blanco Angelus (Angelus Soluciones en Odontología, Londrina, PR, Brazil), preparados de acuerdo con las instrucciones del fabricante. Para los controles, cuatro cavidades apicales fueron obturadas con gutapercha sin sellador de conductos, y los otros 4 con cera pegajosa.

Para prevenir la filtración bacteriana a través de la superficie radicular, se aplicaron dos capas de barniz esmalte de uñas a las superficies laterales externas de todas las raíces. Los dientes fueron radigrafiados para evaluar la calidad de obturación (Fig. 1-11)

\section{Fase de laboratorio:}

Las piezas dentarias ya preparadas fueron colocadas en viales de vidrio esterilizados, conteniendo $10 \mathrm{ml}$ de caldo glucosa (al 5\%) rojo de fenol, sumergiendo solo la zona apical de la raíz en un nivel de 2 ó $3 \mathrm{~mm}$ por encima de la zona apical resecada, fueron sujetados con alambre ligadura y cubiertos con papel de aluminio estéril.

Se inocularon los conductos radiculares de cada diente, vía coronal, con un caldo de cultivo conteniendo la cepa del Enterococcus Faecalis ATCC/29212 cultivada previamente desde el día anterior, y luego fueron incubados a $37^{\circ} \mathrm{C}$, la renovación de los cultivos se realizó cada 7 días, la evaluación de la filtración se realizó cada 24 horas. La filtración de la bacteria desde el conducto radicular hacia el caldo rojo fenol se hacia evidente cuando el color del caldo viraba de rojo a amarillo como resultado de la producción ácida desde el caldo bacteriano.

Para la confirmación de la filtración de Enterococcus Faecalis se procedió al plaqueado del caldo virado en Agar Bilis Esculina y la incubación a temperatura ambiente.

La ejecución de la fase de laboratorio, abarcó un promedio de 120 días, al momento de la redacción del presente informe de investigación continúan aun sin virar los especimenes: amalgama (1), ionómero de vidrio (2), MTA (5).

\section{Resultados}

Tabla 1. Frecuencia de especímenes según material y tiempo de filtración del Enterococcus Faecalis

\begin{tabular}{lcccc}
\hline Grupo experimental & $(1-10)$ días & $(11-35)$ días & $\begin{array}{c}(36-70) \\
\text { días }\end{array}$ & Total \\
\hline Amalgama & 07 & 04 & 01 & 12 \\
Ionómero de vidrio & 06 & 01 & 05 & 12 \\
MTA & 03 & 01 & 08 & 12 \\
TOTAL & 16 & 06 & 14 & 36 \\
\hline
\end{tabular}

$X^{2}: 9,9191 p<0,05$ 
Tabla 2. Filtración en los grupos controles

\begin{tabular}{lccc}
\hline Control & $(1-10)$ días & No filtró & Total \\
\hline Control positivo Gutapercha & 04 & 00 & 04 \\
Control negativo Cera mas barniz & 00 & 04 & 04 \\
\hline
\end{tabular}

La filtración coronaria de la bacteria Enterococcus faecalis, en los especimenes del grupo de control positivo, (obturación hecha con gutapercha) Tabla 2, causó un cambio de color en el caldo glucosa rojo fenol dentro de 1 a 10 días. En contraste, ninguno de los controles negativos (ápices obturados con cera pegajosa y sellados con barniz de uña) causaron el cambio de color.

Los especimenes de obturaciones retrogradas de Amalgama, Ionómero de Vidrio y cemento MTA, permitieron la filtraron del Enterococcus Faecalis dentro de un período de 1 a 70 días. Tabla 1.

La comparación de grupos a través de la prueba $X^{2}$, indica que la frecuencia de especimenes que filtran en tiempos mayores a 70 días es significativamente más alta para los casos de cemento MTA, que para los otros dos materiales.

Los estudios de filtración bacteriana son los recomendados como mas convenientes para probar la efectividad de sellado de potenciales materiales de obturación retrograda, siendo el Enterococus Faecalis una de las bacterias que se le identifica como causante de problemas periapicales.

\section{Discusión}

Torabinejab y col. ${ }^{(7)}$ usaron un estudio de filtración de bacteria para determinar el tiempo necesario para que el Staphyilococcus epidermis penetrara un grosor de $3 \mathrm{~mm}$ de varios materiales de obturación retrograda. Este estudio investigó la habilidad del MTA y varios materiales de obturación retrograda a resistir la contaminación con S. Marcescens.

Todos los grupos de control positivo mostraron un cambio de color que indicó que el sellador de conducto radicular es necesario para mejorar el material de obturación retrograda de gutapercha. Esto también fue mostrado por Beeker y Von Fraunhofer ${ }^{(8)}$ en su estudio con gutapercha termoplástica.
Los especimenes de control negativo que fueron obturados con cera pegajosa no mostraron ningún cambio de color en el caldo rojo de fenol.

Basados en la evidencia de ésta investigación y en estudios previos de filtración bacteriana, afirmamos que el MTA proporcionó un mejor sellado apical como material de obturación retrograda que la amalgama de plata, Ionómero de vidrio ${ }^{(4,7)}$. La habilidad de sellado del MTA podría ser debido a que éste sufre una expansión de fraguado cuando es fraguado en un ambiente húmedo. También se ha hallado que el MTA tiene algún efecto antibacteriano sobre algunas bacterias orales ${ }^{(9)}$, que podría ayudar en su superior habilidad de sellado. Basados en ésta evidencia, al cemento MTA debe dársele una seria consideración, cuando un material de obturación retrograda está indicado.

Al término del estudio se llegó a las siguientes conclusiones:

1. Los tipos de materiales de obturación retrograda que vienen siendo empleados en los tratamientos de Cirugía Apical en la Clínica Central de la facultad de Odontología de la UNMSM son: Amalgama, Ionomero de Vidrio y Gutapercha.

2. En el presente estudio la bacteria Enterococus Faecalis para filtrar corono-apicalmente $3 \mathrm{~mm}$ de obturación retrograda a base de Amalgama empleó un período de 10 a 35 días, y para los cementos Ionomero de Vidrio y MTA, de 10 a 70 días.

3. La frecuencia de especimenes que filtraron el enterococcus faecalis, en tiempos mayores a 70 días fue significativamente más alto para los casos de cemento MTA, que para los otros dos materiales.

4. Los estudios de filtración bacteriana son los recomendados como mas convenientes para probar la efectividad de sellado de potenciales materiales de obturación retrograda, siendo el Enterococus Faecalis una de las bacterias que se le identifica como causante de problemas periapicales.

\section{Referencias bibliográficas}

1. Harty FJ, Parking BJ, Wengraf AM. The success rate of apicoectomy. A retrospective study of 1016 cases. $\mathrm{Br}$ Dent J 1970; 129:407-13

2. Gartner AH, Dorn SO. Advances in endodontic surgery. Dent Clin North Am. 1992; 36:357-79

3. Guttman JL, Harrison JW. Surgical endodontics. Boston: Blackwell Scientific Publications, 1991:238-41

4. Arens DE, Adams WR, DeCastro RA (ods). Endodontic Surgery. Philladelphia; Harper \& Row, 1981:154-7

5. Torabinejab M, Watson TF, Pitt Ford TR. The sealing ability of a mineral trioxide aggregate as a root end filling material. J. Endodon 1993;591-5

6. Chong BS, Pitt Ford TR, Watson TF. The adaptation and sealing ability of light cured glass ionomer retrograde fillings. Int. Endod J. 1991;24:223-32

7. Torabinejab M, Rastegar AF, Kettering JD, Pitt Ford TR. Bacterial Leakage of mineral trioxide aggregate as a root-end filling material. J. Endodon 1995;21:109-12

8. Becker Sa, Von Fraunhofer JA. The comparative leakage behavior reverse filling materials. J. Endodon 1989; 15:245-8

9. Hong CU, Torabinejab M, Kettering JD. The effects of three retrofilling materials on selected bacteria (Abstract 67). J. Endodon 1993;19:200

10. Canalda SC, Brau AE. Endodoncia. Técnicas clínicas y bases científicas. Barcelona: edit Masson. 2001, p. 311

Recibido :02-06-2008

Aceptado para publicación: 12-08-2008 